\title{
Assessing Indicators of Central Obesity as Hypertensive Risk Factors
}

\author{
Alexis Stamatikos ${ }^{\mathrm{a}}$ and Farzad Deyhim ${ }^{\mathrm{b}}$
}

\begin{abstract}
Hypertension, colloquially known as high blood pressure, is a severe public health concern in the United States. Nearly one in three American adults aged 20 or over suffers from hypertension. Hypertension may lead to left ventricular hypertrophy, heart failure, myocardial infarction, cerebral vascular accident, retinopathy, and renal failure. Risk factors for hypertension are numerous and include age, gender, ethnicity, sedentary lifestyle, excessive sodium intake, smoking, diabetes, heavy alcohol consumption, and recreational drug abuse. One of the most familiar markers used as a risk factor for hypertension is obesity based on body mass index. However, while body mass index is easy and inexpensive to apply, it has disadvantages and may not be the best suited marker for certain populations. A better predicting marker for hypertension instead of body mass index may be to measure or estimate intra-abdominal adiposity, commonly known as visceral fat. The clinical name of excessive amounts of adipose tissue around the midsection is central obesity. There are many techniques and procedures to evaluate central obesity, ranging from taking simple measurements and performing straightforward calculations, to utilizing high technologically advanced and expensive equipment. The purpose of this review is to thoroughly assess the rationality of employing central obesity as a risk factor for hypertension and to analyze which diagnostic tests and criteria, if any, are superior compared to others during the testing of both general and special populations.
\end{abstract}

Keywords: Body Mass Index, Central Obesity, Computed Tomography, Dual-Emission X-Ray Absorptiometry, Hypertension, Magnetic Resonance Imaging, Ultrasonography, Waist Circumference, Waist-to-Hip Ratio, Waist-to Stature Ratio

\section{Introduction}

Hypertension (HTN) is currently considered a public health crisis in America, as nearly one in three American adults aged 20 or over suffers from the condition (National Center for Health Statistics, 2010). Additionally, the socioeconomic burdens related to HTN are tremendous, as direct and indirect costs for HTN in the United States are estimated to be 76.6 billion dollars annually (Lloyd-Jones et al., 2010). Furthermore, the dangers of HTN are quite prominent since developing HTN may result in left ventricular hypertrophy, heart failure, myocardial infarction, cerebral vascular accident, retinopathy, and renal failure (Dunn \& Pfeffer, 1999; Ong, Cheung, Man, Lau, \& Lam, 2007; Tso \& Jampol, 1982).

With HTN now being classified as an epidemic in the United States (Choudhry, Fischer, \& Shrank, 2007; Egan, 2004; Fields et al., 2004), it is paramount to set specific risk factors (RF) associated with HTN, so more suitable preventive measures and associated treatments can be appropriately applied to people suffering from HTN. Age, sex, race, lack of physical activity, high dietary sodium intake, heavy use of alcohol, diabetes, smoking, and abuse of recreational drugs are all known to be RF for HTN (Bowman, Gaziano, Buring, \& Sesso, 2007; Burt et al., 1995; Chamarthi, Williams, \& Williams, 2010; Ferdinand, 2000; Ferdinand, 2006; Ghuran \& Nolan, 2000; MacMahon, 1987; Reckelhoff, 2001; Waeber, Feihl, \& Ruilope, 2001; Whelton, Chin, Xin, \& He, 2002). Arguably the most renowned RF for HTN is obesity (Van Itallie, 1985; Steinberger \& Daniels, 2003) defined by body mass index (BMI) (Calle, Thun, Petrelli, Rodriguez, \& Heath Jr., 1999). Research though has shown that BMI may not be a suitable marker for diverse ethnicities and special populations (Deurenberg, Yap, \& van Staveren,
1998; Owen et al., 1990; Deurenberg-Yap, Schmidt, van Staveren, \& Deurenberg, 2000). And while it should be noted that the positive correlation between obesity and HTN is well established (Sharma \& Chetty, 2005), recent findings and hypotheses are starting to address central obesity's (CO) potential role in promoting HTN (Mathieu, Poirier, Pibarot, Lemieux, \& Despres, 2009; Schutte et al., 2010; Balistreri, Caruso, \& Candore, 2010; Pausova et al., 2010; Matsuzawa, 2010; Ibrahim, 2010; Aucouturier, Meyer, Thivel, Taillardat, \& Duche, 2009).

$\mathrm{CO}$ has been established as a core component of the metabolic syndrome (Alberti, Zimmet, \& Shaw, 2006; Balkau \& Charles, 1999; National Cholesterol Education Program, 2001; World Health Organization, 1999) which is important for two reasons; one is that $\mathrm{CO}$ replaced obesity as a core component of metabolic syndrome (National Cholesterol Education Program, 2001; Alberti, Zimmet, \& Shaw, 2006; Balkau \& Charles, 1999) and two, HTN is also considered a core component of metabolic syndrome (National Cholesterol Education Program, 2001; Alberti et al., 2006; Balkau \& Charles, 1999; World Health Organization, 1999). Moreover, since it is hypothesized that $\mathrm{CO}$ is a chief factor in initiating the pathogenesis of other conditions associated with metabolic syndrome (Alberti et al., 2006), with research supporting this (Cameron et al., 2008), it seems plausible to assume that these two conditions are somehow connected with one another in terms of pathophysiology and CO may play a direct role in the development of HTN.

Though CO is generally recognized as the clinical term for excessive accumulation of abdominal fat, other names have been presented to label this anomaly, such as abdominal obesity, truncal obesity, and android obesity. This type of obesity is in contrast to peripheral obesity, which is associated

b. Department of Human Sciences, Texas A\&M University- Kingsville, TX 
with high amounts of subcutaneous adipose tissue. While obesity as a whole is thought to lead to more potentially negative health outcomes than being considered a "healthy weight", $\mathrm{CO}$ is regarded as a greater detriment to health than peripheral obesity. The primary reasoning behind this is assumed to be differences in fat disposition, since fat accumulation in $\mathrm{CO}$ is likely due to high levels of visceral adipose tissue. However, while directly appraising visceral adiposity can only be conducted with certain imaging techniques, measuring and diagnosing $\mathrm{CO}$ can simply be performed using anthropometric data.

The two specific aims of this review are 1) to assess if $C O$ is a stronger marker at predicting HTN than obesity and 2) evaluating which $\mathrm{CO}$ techniques, if any, are superior over one another in predicting HTN in both general and special populations. The exclusive obesity indicator analyzed in this review is BMI, an easy, inexpensive, and widely applied formula used to establish obesity (Smalley, Knerr, Kendrick, Colliver, \& Owen, 1990). The CO methods being evaluated in this review are imaging scans, waist circumference (WC), waist-to-hip ratio (WHR), and waist-to-stature ratio (WSR).

\section{Body Mass Index}

BMI first originated in 1832 as the Quetelet Index from the Belgian statistician, mathematician, and astronomer Adolphe Quetelet (Eknoyan, 2008). In 1972, the Quetelet Index was coined BMI by Ancel Keys (Eknoyan, 2008), which is what it's universally referred to as of present time. Both Quetelet Index and BMI are simply calculated by kilograms in weight over height in meters squared (Eknoyan, 2008). In clinical settings, BMI is a procedure used extensively to determine obesity due to its ease and low economical cost (Smalley et al., 1990).

Though BMI may sometimes be an adequate marker for obesity diagnosis in the general public, certain populations would more than likely result in misdiagnoses when utilizing BMI. These populations include muscular individuals, ascites patients, pregnant females, people with edema, and elderly suffering from either sarcopenia or sarcopenic obesity. The rationale behind BMI not being a valuable marker for these individuals lies in the fact that Adolphe Quetelet invented his Quetelet Index to identify distinctiveness of average weight to height and provide distribution around what is considered average weight to respecting height, not be exploited to establish obesity (Eknoyan, 2008).

BMI has also come into question when being used for different races to establish obesity. In particular, evidence has shown that BMI may not be a reliable obesity marker for the Chinese, African Americans, Indians, Malays, Ethiopians, Thais, Polynesians, and Indonesians (Deurenberg-Yap et al., 2000; Deurenberg et al., 1998). The reason for BMI being such a poor indicator in these ethnicities might be because the data pooled by Adolphe Quetelet to construct his Quetelet Index was mainly from Anglo-Saxon populaces (Eknoyan, 2008). Additionally, in direct relation to this review, not only has data supported possibly establishing different BMI cut-out points for various ethnicities to use as a RF for HTN (Bell, Adair, \& Popkin, 2002), there have also been inconsistencies to link a positive association between HTN and BMI (Kaufman et al., 1997; Hu et al., 2004; Tesfaye et al., 2007).

\section{Central Obesity Diagnostic Criteria}

Imaging Scans

Magnetic resonance imaging (MRI), computed tomography (CT), dual-emission X-ray absorptiometry (DXA), and ultrasonography (US) are different types of imaging scans that can all be employed to appraise CO. Both MRI and CT scans are highly dependable and extremely accurate when measuring CO (Ohsuzu et al., 1998; Seidell, Bakker, \& van der Kooy, 1990). Briefly, MRI works by utilizing the signal from hydrogen atoms nuclei to produce images (Weishaupt, Kochli, \& Marincek, 2008). CT operates by using data acquired from the measurements of the attenuation of $\mathrm{x}$-rays along numerous cross sectional lines to generate images of the human body (Herman, 2009).

Downfalls to MRI and CT scans are the lack of general accessibility and expense of the procedures. Additionally, CT runs the risk of patients being exposed to ionizing radiation, which is officially recognized to be a known human carcinogen (United States Department of Health and Human Services, 2005), and appears to be less accurate than MRI for numerous conditions (Kidwell et al., 2004; Lubovsky, Liebergall, Mattan, Weil, \& Mosheiff, 2005; Aisen et al., 1986). Though, in terms of assessing visceral adipose tissue, it is debatable as to whether MRI or CT appears to be the most accurate technique to employ out of all the imaging scans for measuring CO (Ohsuzu et al., 1998; Ross, Leger, Morris, de Guise, \& Guardo, 1992; Wajchenberg, 2000; Cascella et al., 2008). However, MRI procedures are known to last longer than CT scans and generally cost more, too.

An easier, cheaper, and more accessible technique than both MRI and CT to appraise abdominal adiposity is DXA (Vatanparast et al., 2009). While DXA does emit ionizing radiation as it employs the use of $\mathrm{X}$-rays, the exposure is much less than that of a CT scan (Njeh, Fuerst, Hans, Blake, \& Genant, 1999). Furthermore, DXA is less time consuming compared to MRI. A disadvantage to DXA on top of exposing patients to ionizing radiation is that it is not as accurate and reliable as CT or MRI when evaluating abdominal fat mass (Taylor, Jones, Williams, \& Goulding, 2000), particularly visceral adiposity (Browning et al., 2011; Jensen, Kanaley, Reed, \& Sheedy, 1995), the type of fat presumed to lead to an array of health problems, including HTN.

US, a procedure using sound waves that is well known to be implemented during pregnancy to produce images of embryos and fetuses, can also be used to measure abdominal fat. Advantages to US are it's a relatively inexpensive procedure compared to MRI and CT, plus doesn't emit any ionizing radiation. US has also been shown to effectively evaluate $\mathrm{CO}$ appreciable to $\mathrm{CT}$ and MRI measurements (Cucchi et al., 1997; Gong et al., 2007; Ribeiro-Filho et al., 2001), but typically takes longer to perform than CT scans and DXA. However, a recent accurate technique to measure visceral fat via US has made the procedure comparable, or even faster than both DXA and CT (Zhou et al., 2010).

Imaging scans are considered superior compared to anthropometric values when analyzing visceral adipose tissue (Iacobellis, 2005). Therefore, if a precise CO evaluation is warranted, then employing imaging scans should be top priority. To the authors' knowledge, there have been no studies conducted with prime interest to directly assess the 
variability and reliability of imaging scans on visceral adipose tissue in pertinence to provide a positive correlation with HTN. However, it seems plausible to assume that CO diagnoses by imaging scans to be highly associated with HTN, since CO is thought to promote the initiation of HTN and other core components of the metabolic syndrome (Alberti et al., 2006).

\section{Waist Circumference}

$\mathrm{WC}$ is a very common procedure for measuring CO. Moreover, WC is recognized to be the approved method to measure $\mathrm{CO}$ for the International Diabetes Federation, European Group for the Study of Insulin Resistance, and the National Cholesterol Education Program (Balkau \& Charles, 1999; Alberti et al., 2006; National Cholesterol Education Program, 2001). Since CO diagnosis using WC only needs one simple measurement to be performed, it can be considered the easiest, quickest way to identify CO. Well known CO cutoff measurements in America advised by both the United States Department of Agriculture and American Heart Association are $102 \mathrm{~cm}$ for males and $88 \mathrm{~cm}$ for females (Zhang, Rexrode, van Dam, Li, \& Hu, 2008).

Using WC to detect CO correlating with HTN has shown to produce favorable results (Guagnano et al., 2001; Janssen, Katzmarzyk, \& Ross, 2002; Poirier et al., 2005). However, diagnosis of $\mathrm{CO}$ utilizing $\mathrm{WC}$ appears to be different in various races (Lee et al., 2007; Tan, Ma, Wai, Chew, \& Tai, 2004; Snehalatha, Viswanathan, \& Ramachandran, 2003; Examination Committee of Criteria for 'Obesity Disease' in Japan, 2002), suggesting that different cutoff points should be incorporated for specific populations (Misra, Wasir, \& Vikram, 2005). To potentially counter this, WC values have been modified for different ethnicities by the International Diabetes Federation to try and establish more precise diagnostic criteria for $\mathrm{CO}$ in diverse populations (Alberti et al., 2006). However, having different cutoffs for various races may pose a problem for lay people as the racial and ethnic classifications set in place by the International Diabetes Federation may be confusing. Another quandary of WC is its strong correlation with BMI for certain conditions (van Dis, Kromhout, Geleijnse, Boer, \& Verschuren, 2009; Farin, Abbasi, \& Reaven, 2005), which may sometimes make measuring WC inane. And though it may seem conceivable to contemplate as WC increases, so would HTN. However, this assertion is not always true mainly due to height differences

\section{Waist-to-Hip Ratio}

WHR is another technique to measure $\mathrm{CO}$ that takes into account height disparities among individuals. Additionally, adipose tissue surrounding the hips, buttocks, and thighs that gives a "pear shape" appearance is thought to be less harmful to health than fat located in the midsection which gives a more "apple shape" figure (Arner, 1997; Kissebah \& Krakower, 1994). A more clinical name for pear shape is gynoid shape and for apple shape it is android shape. Pear shape fat distribution is predominately seen more in premenopausal women than men or postmenopausal women likely due to hormonal differences between the three groups (Tchernof, 2010; Sites \& McKinney, 2008; Blouin, Boivin, \& Tchernof, 2008; Ley, Lees, \& Stevenson, 1992; Lindberg, Crona, Silfverstolpe, Bjorntorp, \& Rebuffe-Scrive, 1990).
Furthermore, the risk of cardiovascular disease is far less for premenopausal women compared to men, but once women experience menopause, cardiovascular risk significantly rises (Rosano, Vitale, Marazzi, \& Volterrani, 2007). Though a WHR cutoff of 0.95 for men and 0.88 for women were recommended by the American Heart Association and the US Department of Agriculture (Zhang et al., 2008), the World Health Organization identifies CO diagnosis using $>0.90$ for men and > 0.85 for women (World Health Organization, 1999). WHR has displayed extreme variability at predicting HTN when used as a CO marker (Janssen et al., 2002; Faria, Ribeiro Filho, Gouveia, Sr., \& Zanella, 2002; Esmaillzadeh, Mirmiran, \& Azizi, 2004; Bonora et al., 1996; Stevens, Gautman, \& Keil, 1993; Nemesure, Wu, Hennis, \& Leske, 2008; Guagnano et al., 2001). Speculations by the authors as to why such variability may be found using WHR as a CO marker to diagnose HTN is explained in detail later in the "discussions" section.

\section{Waist-to-Stature Ratio}

WSR, also known as waist-to-height ratio, is a relatively new concept using anthropometric data to measure $\mathrm{CO}$ compared to WC and WHR. Since height is a routine medical measurement in the clinical field, WSR is very comparable to WC in terms of convenience and likely patients would feel more comfortable with only having a waist measurement taken instead of both their waist and hip measurements. Since WSR is a rather novel tool to diagnose $\mathrm{CO}$, general consensus on a universal cutoff value as well as if ratios should change for age, gender, and race/ethnicity have yet to be determined.

WSR has shown promise to be a dependable RF for HTN. Studies have supported a correlation between CO diagnosis from WSR and HTN (Ashwell \& Gibson, 2009; Hsieh \& Muto, 2006; Rodrigues, Baldo, \& Mill, 2010). Overall, WSR may appear to be the best CO diagnostic instrument to incorporate in the medical field due to its simplicity, cost-effectiveness, and potential reliability in diverse populations, since it takes height into account.

\section{Discussions}

From literature reviewed, it is suggested by the authors that $\mathrm{CO}$ should replace BMI as a RF for HTN and BMI should only be aptly substituted in the case where information to diagnose $\mathrm{CO}$ cannot be obtained, or when $\mathrm{CO}$ may be falsely recorded, such as with ascites. Not only are $\mathrm{CO}$ and HTN linked to one another with the metabolic syndrome (World Health Organization, 1999; Balkau \& Charles, 1999; Alberti et al., 2006; National Cholesterol Education Program, 2001), it is hypothesized that CO may trigger the pathogenesis of all other metabolic syndrome conditions, which would include HTN (Alberti et al., 2006). Evidence has even supported the notion of $\mathrm{CO}$ initiating HTN and other metabolic syndrome conditions (Cameron et al., 2008).

Information presented in this review may be pertinent to clinicians. $\mathrm{CO}$ can be considered more of a visual and physical RF, which provides clinicians more objective material as compared to subjective information, such as diet and exercise history. Therefore, it offers clinicians who have patients diagnosed with $\mathrm{CO}$ who are also hypertensive a marker for both the patient and clinician to properly assign 
unique strategies, goals, and objectives to reduce $\mathrm{CO}$ with the intent to decrease patient blood pressure

There are mechanisms of action pertaining to visceral fat, the type of adipose tissue attempted to be measured for $\mathrm{CO}$ diagnosis, that could potentially contribute to developing HTN. Visceral adipose tissue is thought to increase activity of the sympathetic nervous system (Duvnjak, Bulum, \& Metelko, 2008), that may cause vasoconstriction and raise blood pressure. Additionally, it has been suggested that visceral obesity may negatively alter the renin-angiotensin system (Mathieu, Poirier, Pibarot, Lemieux, \& Despres, 2009), possibly resulting in raising blood pressure via vasoconstriction. Evidence has supported visceral adipose tissue to express mRNA angiotensinogen markedly higher than subcutaneous fat (Giacchetti et al., 2000; Giacchetti et al., 2002), as well as exhibit significantly higher mRNA levels of angiotensin II receptor type 1 (Giacchetti et al., 2002). The vasoconstrictive characteristics of visceral fat that arise from abnormalities in the sympathetic nervous system and reninangiotensin system may have a synergistic effect upon increasing blood pressure that may result in HTN.

It is still questionable as to which $\mathrm{CO}$ marker should be used as a RF for HTN. In light of this review it appears that diagnosing $\mathrm{CO}$ by utilizing WSR in the clinical setting may be the best predictor for HTN. However, since WSR is a relatively novel indicator of $\mathrm{CO}$, it is too soon to presume it is superior to other anthropometric measurements. Furthermore, CO measurement value cutoffs for different age groups, gender, and races/ethnicities haven't be agreed upon for WSR, let alone a general standard cutoff value. Future studies may discover copious optimal CO cutoff values for WSR in various populations, which might make employing WSR for clinical use infeasible.

In terms of WC, a standard cutoff point may seem to be appropriate for most populations of normal height in determining CO status as a RF for HTN. However, evidence does suggest that race influences the amount of visceral fat present in a particular individual (Hill et al., 1999; Park, Allison, Heymsfield, \& Gallagher, 2001). If this proves to be the case, then different $\mathrm{CO}$ cutoff values for various races and ethnicities may need to be imposed to correctly diagnose CO. And though the International Diabetes Federation has defined CO cutoffs for basic ethnic groups (Alberti et al., 2006), future studies need to be conducted so updates can be made upon their general recommendations.

It appears that WHR may in fact have the largest variability in being used as a RF for HTN when establishing $\mathrm{CO}$ than any of the other anthropometric measurements previously discussed. The reason for this is rather straightforward, as even someone with an excessive amount of visceral fat contributing to a large waist circumference might be overshadowed with an extremely sizeable hip circumference, resulting in $\mathrm{CO}$ being undiagnosed. On the contrary, individuals who naturally have very small hips, buttocks, and thighs but a larger abdominal trunk that doesn't hold excessive visceral fat may get misdiagnosed as having CO. It should also be addressed that recent evidence has shown hip circumference to not have protective qualities against male gender (Yang et al., 2010). This is an importance implication in regards to WHR, since having a larger hip circumference to waist circumference is in theory a healthier trait to possess. This suggests that WHR may be a better diagnostic instrument to employ in the clinical setting with females only.

Although imaging scans may provide better analyses of visceral fat in patients, it is too costly and unmanageable to screen each patient for $\mathrm{CO}$ using imaging scans during routine physician examinations. It is recommended by the authors that imaging scans should only be incorporated during studies that rely on the most accurate measurement of $\mathrm{CO}$, when anthropometric measurements are thought to be impractical to properly diagnose $\mathrm{CO}$ due to certain diagnoses (e.g. edema), or when a physician or general practitioner is still in doubt of assessing a patient's CO status even after anthropometric data to evaluate WC, WHR, and WSR have been performed.

\section{Conclusions}

This review proposes the concept of $\mathrm{CO}$ replacing $\mathrm{BMI}$ as a RF for HTN. However, which CO technique to employ is still questionable. Until new data emerges in regards to WSR to gender and various ethnicities and races, a default standard of $\geq 0.50$ for WSR to diagnose CO in the clinical setting is recommended, with the simple concept to remember, "keep your waist circumference to less than half your height" (Ashwell \& Hsieh, 2005; McCarthy \& Ashwell, 2006). Physicians using either WC or WHR to diagnose CO should be proceed with caution due to potentially significant discrepancies for height and gender respectively, in addition to race and ethnicity as well, which may ultimately come down to a "judgment call" diagnosis for general practitioners who utilize these $\mathrm{CO}$ anthropometric markers.

In general, imaging scans should only be reserved for when $\mathrm{CO}$ diagnosis is disputable after $\mathrm{CO}$ anthropometric data has been evaluated or when the most precise $\mathrm{CO}$ measurements are needed, as during specific studies. It is advised by the authors that DXA and CT scans only be limited to adults when assessing $\mathrm{CO}$ as they emit ionizing radiation, which can cause cancer (United States Department of Health and Human Services, 2005). Since the cells of children and adolescents rapidly divide more so than adults on top of cancer sometimes taking years or even decades to form, employing CT scans or DXA just to measure CO in adolescents and children seems ill-advised. More appropriate means to measure $\mathrm{CO}$ in both children and adolescents when imaging scans are warranted would be to use either MRI or US. Three other main deciding factors to consider when utilizing imaging scans to diagnose $\mathrm{CO}$, only after ionizing radiation issues, are reliability, time, and cost. Either MRI or CT scan is most appropriate when the most precise CO measurement needs to be performed, as differences between the two are likely to be negligible. Unfortunately, if cost is a concern, then employing either CT scans or MRI to assess CO may be unrealistic due to the high operating rates of these machines. Lastly, time needs to be addressed as well, since the period needed to complete MRI or US will typically take longer compared to CT scans or DXA. Fortunately, a novel and accurate technique that employs US to appraise visceral fat has been constructed, which rivals CT and DXA in rapidity (Zhou et al., 2010). These four main factors, with ionizing radiation especially being the prime concern with adolescents and children, always need to be contemplated when utilizing imaging scans to measure $\mathrm{CO}$, whether if it is for only one person, or one-thousand. 


\section{Acknowledgements}

The authors thank Dr. Kathleen Rees for her critical reading of the manuscript. A majority of this manuscript was completed when Alexis Stamatikos was a graduate student for Dr. Farzad Deyhim at Texas A\&M University- Kingsville.

\section{References}

Aisen, A. M., Martel, W., Braunstein, E. M., McMillin, K. I., Phillips, W. A., \& Kling, T. F. (1986). MRI and CT evaluation of primary bone and soft-tissue tumors. AJR Am.J Roentgenol., 146, 749-756.

Alberti, K. G., Zimmet, P., \& Shaw, J. (2006). Metabolic syndrome--a new world-wide definition. A Consensus Statement from the International Diabetes Federation. Diabet.Med., 23, 469-480.

Arner, P. (1997). Regional adipocity in man. J.Endocrinol., 155, 191-192.

Ashwell, M. \& Gibson, S. (2009). Waist to height ratio is a simple and effective obesity screening tool for cardiovascular risk factors: Analysis of data from the British National Diet And Nutrition Survey of adults aged 19-64 years. Obes.Facts., 2, 97-103.

Ashwell, M. \& Hsieh, S. D. (2005). Six reasons why the waist-to-height ratio is a rapid and effective global indicator for health risks of obesity and how its use could simplify the international public health message on obesity. Int.J Food Sci.Nutr., 56, 303-307.

Aucouturier, J., Meyer, M., Thivel, D., Taillardat, M., \& Duche, P. (2009). Effect of android to gynoid fat ratio on insulin resistance in obese youth. Arch. Pediatr. Adolesc. Med., 163, 826-831.

Balistreri, C. R., Caruso, C., \& Candore, G. (2010). The role of adipose tissue and adipokines in obesity-related inflammatory diseases. Mediators.Inflamm., 2010, 802078.

Balkau, B. \& Charles, M. A. (1999). Comment on the provisional report from the WHO consultation. European Group for the Study of Insulin Resistance (EGIR). Diabet.Med., 16, 442-443.

Bell, A. C., Adair, L. S., \& Popkin, B. M. (2002). Ethnic Difference in the Association between Body Mass Index and Hypertension. American Journal of Epidemiology, 155, 346-353.

Blouin, K., Boivin, A., \& Tchernof, A. (2008). Androgens and body fat distribution. J Steroid Biochem.Mol.Biol., 108, 272-280.

Bonora, E., Targher, G., Branzi, P., Zenere, M., Saggiani, F., Zenti, M. G. et al. (1996). Cardiovascular risk profile in 38 -year and 18-year-old men. Contribution of body fat content and regional fat distribution. Int.J Obes.Relat Metab Disord., 20, 28-36.

Bowman, T. S., Gaziano, J. M., Buring, J. E., \& Sesso, H. D. (2007). A prospective study of cigarette smoking and risk of incident hypertension in women. $J$ Am.Coll.Cardiol., 50, 2085-2092.

Browning, L. M., Mugridge, O., Dixon, A. K., Aitken, S. W., Prentice, A. M., \& Jebb, S. A. (2011). Measuring abdominal adipose tissue: comparison of simpler methods with MRI. Obes.Facts., 4, 9-15.
Burt, V. L., Whelton, P., Roccella, E. J., Brown, C., Cutler, J. A., Higgins, M. et al. (1995). Prevalence of hypertension in the US adult population. Results from the Third National Health and Nutrition Examination Survey, 1988-1991. Hypertension, 25, 305-313.

Calle, E. E., Thun, M. J., Petrelli, J. M., Rodriguez, C., \& Heath Jr., C. W. (1999). Body-mass index and mortality in a prospective cohort of U.S. adults. N.Engl.J.Med., 341, 1097-1105.

Cameron, A. J., Boyko, E. J., Sicree, R. A., Zimmet, P. Z., Soderberg, S., Alberti, K. G. et al. (2008). Central obesity as a precursor to the metabolic syndrome in the AusDiab study and Mauritius. Obesity.(Silver.Spring), 16, 2707-2716.

Cascella, T., Palomba, S., De, S., I, Manguso, F., Giallauria, F., De, S. B. et al. (2008). Visceral fat is associated with cardiovascular risk in women with polycystic ovary syndrome. Hum.Reprod., 23, 153-159.

Chamarthi, B., Williams, J. S., \& Williams, G. H. (2010). A mechanism for salt-sensitive hypertension: abnormal dietary sodium-mediated vascular response to angiotensin-II. J Hypertens., 28, 1020-1026.

Choudhry, N. K., Fischer, M. A., \& Shrank, W. H. (2007). Controlling the hypertension epidemic: Regimens with the best efficacy, tolerability, and affordability: A practical review of current data Pennsylvania Department of Aging: Alosa Foundation, Independent Drug Information Service.

Cucchi, E., Piatti, P. M., Orena, C., Pontiroli, A. E., Martino, E., Paesano, P. L. et al. (1997). [Is echography an adequate method for assessing the thickness of intraabdominal fat? A comparison with computed tomography]. [Article in Italian]. Radiol.Med., 94, 329334.

Deurenberg, P., Yap, M., \& van Staveren, W. A. (1998). Body mass index and percent body fat: a meta analysis among different ethnic groups. Int.J Obes.Relat Metab Disord., 22, 1164-1171.

Deurenberg-Yap, M., Schmidt, G., van Staveren, W. A., \& Deurenberg, P. (2000). The paradox of low body mass index and high body fat percentage among Chinese, Malays and Indians in Singapore. Int.J Obes.Relat Metab Disord., 24, 1011-1017.

Dunn, F. G. \& Pfeffer, M. A. (1999). Left ventricular hypertrophy in hypertension. N.Engl.J Med., 340, 12791280.

Duvnjak, L., Bulum, T., \& Metelko, Z. (2008). Hypertension and the Metabolic Syndrome. Diabetologia Croatica, 37, 83-89.

Egan, B. M. (2004). Hypertension in the 21st century: the tide is rising; our daze must end. Hypertension, 44, 389.

Eknoyan, G. (2008). Adolphe Quetelet (1796-1874)--the average man and indices of obesity. Nephrol.Dial.Transplant., 23, 47-51.

Esmaillzadeh, A., Mirmiran, P., \& Azizi, F. (2004). Waist-tohip ratio is a better screening measure for cardiovascular risk factors than other anthropometric indicators in Tehranian adult men. Int.J Obes.Relat Metab Disord., 28, 1325-1332.

Examination Committee of Criteria for 'Obesity Disease' in Japan (2002). New criteria for 'obesity disease' in Japan. Circ J, 66, 987-992. 
Faria, A. N., Ribeiro Filho, F. F., Gouveia, F., Sr., \& Zanella, M. T. (2002). Impact of visceral fat on blood pressure and insulin sensitivity in hypertensive obese women. Obes.Res., 10, 1203-1206.

Farin, H. M., Abbasi, F., \& Reaven, G. M. (2005). Body mass index and waist circumference correlate to the same degree with insulin-mediated glucose uptake. Metabolism, 54, 1323-1328.

Ferdinand, K. C. (2000). Substance Abuse and Hypertension. J Clin.Hypertens.(Greenwich.), 2, 37-40.

Ferdinand, K. C. (2006). Hypertension in minority populations. J Clin.Hypertens.(Greenwich.), 8, 365-368.

Fields, L. E., Burt, V. L., Cutler, J. A., Hughes, J., Roccella, E. J., \& Sorlie, P. (2004). The burden of adult hypertension in the United States 1999 to 2000: a rising tide. Hypertension, 44, 398-404.

Ghuran, A. \& Nolan, J. (2000). The cardiac complications of recreational drug use. West J Med., 173, 412-415.

Giacchetti, G., Faloia, E., Mariniello, B., Sardu, C., Gatti, C., Camilloni, M. A. et al. (2002). Overexpression of the renin-angiotensin system in human visceral adipose tissue in normal and overweight subjects. Am.J.Hypertens., 15, 381-388.

Giacchetti, G., Faloia, E., Sardu, C., Camilloni, M. A., Mariniello, B., Gatti, C. et al. (2000). Gene expression of angiotensinogen in adipose tissue of obese patients. Int.J.Obes.Relat Metab Disord., 24 Suppl 2, S142-S143.

Gong, W., Ren, H., Tong, H., Shen, X., Luo, J., Chen, S. et al. (2007). A comparison of ultrasound and magnetic resonance imaging to assess visceral fat in the metabolic syndrome. Asia Pac.J Clin.Nutr., 16 Suppl 1, 339-345.

Guagnano, M. T., Ballone, E., Colagrande, V., Della, V. R., Manigrasso, M. R., Merlitti, D. et al. (2001). Large waist circumference and risk of hypertension. Int.J Obes.Relat Metab Disord., 25, 1360-1364.

Herman, G. T. (2009). Fundamentals of computerized tomography: Image reconstruction from projection. (2nd ed.) London: Spinger-Verlag.

Hill, J. O., Sidney, S., Lewis, C. E., Tolan, K., Scherzinger, A. L., \& Stamm, E. R. (1999). Racial differences in amounts of visceral adipose tissue in young adults: the CARDIA (Coronary Artery Risk Development in Young Adults) study. Am.J Clin.Nutr., 69, 381-387.

Hsieh, S. D. \& Muto, T. (2006). Metabolic syndrome in Japanese men and women with special reference to the anthropometric criteria for the assessment of obesity: Proposal to use the waist-to-height ratio. Prev.Med., 42, 135-139.

Hu, G., Barengo, N. C., Tuomilehto, J., Lakka, T. A., Nissinen, A., \& Jousilahti, P. (2004). Relationship of physical activity and body mass index to the risk of hypertension: a prospective study in Finland. Hypertension, 43, 25-30.

Iacobellis, G. (2005). Imaging of visceral adipose tissue: an emerging diagnostic tool and therapeutic target. Curr.Drug Targets.Cardiovasc.Haematol.Disord., 5, 345-353.

Ibrahim, M. M. (2010). Subcutaneous and visceral adipose tissue: structural and functional differences. Obes.Rev., $11,11-18$

Janssen, I., Katzmarzyk, P. T., \& Ross, R. (2002). Body mass index, waist circumference, and health risk: evidence in support of current National Institutes of Health guidelines. Arch.Intern.Med., 162, 2074-2079.

Jensen, M. D., Kanaley, J. A., Reed, J. E., \& Sheedy, P. F. (1995). Measurement of abdominal and visceral fat with computed tomography and dual-energy x-ray absorptiometry. Am.J Clin.Nutr., 61, 274-278.

Kaufman, J. S., Asuzu, M. C., Mufunda, J., Forrester, T., Wilks, R., Luke, A. et al. (1997). Relationship between blood pressure and body mass index in lean populations. Hypertension, 30, 1511-1516.

Kidwell, C. S., Chalela, J. A., Saver, J. L., Starkman, S., Hill, M. D., Demchuk, A. M. et al. (2004). Comparison of MRI and CT for detection of acute intracerebral hemorrhage. JAMA, 292, 1823-1830.

Kissebah, A. H. \& Krakower, G. R. (1994). Regional adiposity and morbidity. Physiol Rev., 74, 761-811.

Lee, S. Y., Park, H. S., Kim, D. J., Han, J. H., Kim, S. M., Cho, G. J. et al. (2007). Appropriate waist circumference cutoff points for central obesity in Korean adults. Diabetes Res.Clin.Pract., 75, 72-80.

Ley, C. J., Lees, B., \& Stevenson, J. C. (1992). Sex- and menopause-associated changes in body-fat distribution. Am.J Clin.Nutr., 55, 950-954.

Lindberg, U. B., Crona, N., Silfverstolpe, G., Bjorntorp, P., \& Rebuffe-Scrive, M. (1990). Regional adipose tissue metabolism in postmenopausal women after treatment with exogenous sex steroids. Horm.Metab Res., 22, 345351.

Lloyd-Jones, D., Adams, R. J., Brown, T. M., Carnethon, M., Dai, S., De, S. G. et al. (2010). Heart disease and stroke statistics--2010 update: a report from the American Heart Association. Circulation, 121, e46-e215.

Lubovsky, O., Liebergall, M., Mattan, Y., Weil, Y., \& Mosheiff, R. (2005). Early diagnosis of occult hip fractures MRI versus CT scan. Injury, 36, 788-792.

MacMahon, S. (1987). Alcohol consumption and hypertension. Hypertension, 9, 111-121.

Mathieu, P., Poirier, P., Pibarot, P., Lemieux, I., \& Despres, J. P. (2009). Visceral obesity: the link among inflammation, hypertension, and cardiovascular disease. Hypertension, 53, 577-584.

Matsuzawa, Y. (2010). Establishment of a concept of visceral fat syndrome and discovery of adiponectin. Proc.Jpn.Acad.Ser.B Phys.Biol.Sci., 86, 131-141.

McCarthy, H. D. \& Ashwell, M. (2006). A study of central fatness using waist-to-height ratios in UK children and adolescents over two decades supports the simple message--'keep your waist circumference to less than half your height'. Int.J Obes.(Lond), 30, 988-992.

Misra, A., Wasir, J. S., \& Vikram, N. K. (2005). Waist circumference criteria for the diagnosis of abdominal obesity are not applicable uniformly to all populations and ethnic groups. Nutrition, 21, 969-976.

National Center for Health Statistics (2010). Health, United States, 2009: With Special Feature on Medical Technology Huntsville, MD: Secretary of the Department of Health and Human Services.

National Cholesterol Education Program (2001). Executive Summary of The Third Report of The National Cholesterol Education Program (NCEP) Expert Panel on Detection, Evaluation, And Treatment of High Blood 
Cholesterol In Adults (Adult Treatment Panel III). JAMA, 285, 2486-2497.

Nemesure, B., Wu, S. Y., Hennis, A., \& Leske, M. C. (2008). The relationship of body mass index and waist-hip ratio on the 9-year incidence of diabetes and hypertension in a predominantly African-origin population. Ann.Epidemiol., 18, 657-663.

Njeh, C. F., Fuerst, T., Hans, D., Blake, G. M., \& Genant, H. K. (1999). Radiation exposure in bone mineral density assessment. Appl.Radiat.Isot., 50, 215-236.

Ohsuzu, F., Kosuda, S., Takayama, E., Yanagida, S., Nomi, M., Kasamatsu, H. et al. (1998). Imaging techniques for measuring adipose-tissue distribution in the abdomen: a comparison between computed tomography and 1.5-tesla magnetic resonance spin-echo imaging. Radiat.Med., 16, 99-107.

Ong, K. L., Cheung, B. M., Man, Y. B., Lau, C. P., \& Lam, K. S. (2007). Prevalence, awareness, treatment, and control of hypertension among United States adults 1999-2004. Hypertension, 49, 69-75.

Owen, O. E., Smalley, K. J., D'Alessio, D. A., Mozzoli, M. A., Knerr, A. N., Kendrick, Z. V. et al. (1990). Resting metabolic rate and body composition of achondroplastic dwarfs. Medicine (Baltimore), 69, 56-67.

Park, Y. W., Allison, D. B., Heymsfield, S. B., \& Gallagher, D. (2001). Larger amounts of visceral adipose tissue in Asian Americans. Obes.Res., 9, 381-387.

Pausova, Z., Abrahamowicz, M., Mahboubi, A., Syme, C., Leonard, G. T., Perron, M. et al. (2010). Functional variation in the androgen-receptor gene is associated with visceral adiposity and blood pressure in male adolescents. Hypertension, 55, 706-714.

Poirier, P., Lemieux, I., Mauriege, P., Dewailly, E., Blanchet, C., Bergeron, J. et al. (2005). Impact of waist circumference on the relationship between blood pressure and insulin: the Quebec Health Survey. Hypertension, 45, 363-367.

Reckelhoff, J. F. (2001). Gender differences in the regulation of blood pressure. Hypertension, 37, 1199-1208.

Ribeiro-Filho, F. F., Faria, A. N., Kohlmann, O., Jr., Ajzen, S., Ribeiro, A. B., Zanella, M. T. et al. (2001). Ultrasonography for the evaluation of visceral fat and cardiovascular risk. Hypertension, 38, 713-717.

Rodrigues, S. L., Baldo, M. P., \& Mill, J. G. (2010). Association of waist-stature ratio with hypertension and metabolic syndrome: population-based study. Arq Bras.Cardiol., 95, 186-191.

Rosano, G. M., Vitale, C., Marazzi, G., \& Volterrani, M. (2007). Menopause and cardiovascular disease: the evidence. Climacteric., 10 Suppl 1, 19-24.

Ross, R., Leger, L., Morris, D., de Guise J., \& Guardo, R. (1992). Quantification of adipose tissue by MRI: relationship with anthropometric variables. $J$ Appl.Physiol, 72, 787-795.

Schutte, A. E., Huisman, H. W., Schutte, R., van Rooyen, J. M., Malan, L., Fourie, C. M. et al. (2010). Adipokines and cardiometabolic function: How are they interlinked? Regul.Pept., 164, 133-138.

Seidell, J. C., Bakker, C. J., \& van der Kooy, K. (1990). Imaging techniques for measuring adipose-tissue distribution--a comparison between computed tomography and 1.5-T magnetic resonance. Am.J Clin.Nutr., 51, 953-957.

Sharma, A. M. \& Chetty, V. T. (2005). Obesity, hypertension and insulin resistance. Acta Diabetol., 42 Suppl 1, S3-S8.

Sites, C. K. \& McKinney, S. L. (2008). The Metabolic Syndrome: Impact on women and considerations for treatment. Menopausal Medicine, 16, S1, S3-S7.

Smalley, K. J., Knerr, A. N., Kendrick, Z. V., Colliver, J. A., \& Owen, O. E. (1990). Reassessment of body mass indices. Am.J Clin.Nutr., 52, 405-408.

Snehalatha, C., Viswanathan, V., \& Ramachandran, A. (2003). Cutoff values for normal anthropometric variables in asian Indian adults. Diabetes Care, 26, 1380-1384.

Steinberger, J. \& Daniels, S. R. (2003). Obesity, insulin resistance, diabetes, and cardiovascular risk in children: an American Heart Association scientific statement from the Atherosclerosis, Hypertension, and Obesity in the Young Committee (Council on Cardiovascular Disease in the Young) and the Diabetes Committee (Council on Nutrition, Physical Activity, and Metabolism). Circulation, 107, 1448-1453.

Stevens, J., Gautman, S. P., \& Keil, J. E. (1993). Body mass index and fat patterning as correlates of lipids and hypertension in an elderly, biracial population. $J$ Gerontol., 48, M249-M254.

Tan, C. E., Ma, S., Wai, D., Chew, S. K., \& Tai, E. S. (2004). Can we apply the National Cholesterol Education Program Adult Treatment Panel definition of the metabolic syndrome to Asians? Diabetes Care, 27, 11821186.

Taylor, R. W., Jones, I. E., Williams, S. M., \& Goulding, A. (2000). Evaluation of waist circumference, waist-to-hip ratio, and the conicity index as screening tools for high trunk fat mass, as measured by dual-energy X-ray absorptiometry, in children aged 3-19 у. Am.J Clin.Nutr., $72,490-495$.

Tchernof, A. (2010). Sex Differences in Energy Balance, Body Composition, and Body Fat Distribution. In A.Tsatsoulis, J. Wyckoff, \& F. M. Brown (Eds.), Diabetes in Women (pp. 1-24). Humana Press.

Tesfaye, F., Nawi, N. G., Van, M. H., Byass, P., Berhane, Y., Bonita, R. et al. (2007). Association between body mass index and blood pressure across three populations in Africa and Asia. J Hum.Hypertens., 21, 28-37.

Tso, M. O. \& Jampol, L. M. (1982). Pathophysiology of hypertensive retinopathy. Ophthalmology, 89, 11321145.

United States Department of Health and Human Services, P. H. S. N. T. P. (2005). Report on Carcinogens, Eleventh Edition.

Van Itallie, T. B. (1985). Health implications of overweight and obesity in the United States. Ann.Intern.Med., 103, 983-988.

van Dis, I., Kromhout, D., Geleijnse, J. M., Boer, J. M., \& Verschuren, W. M. (2009). Body mass index and waist circumference predict both 10-year nonfatal and fatal cardiovascular disease risk: study conducted in 20,000 Dutch men and women aged 20-65 years. Eur.J Cardiovasc.Prev.Rehabil., 16, 729-734.

Vatanparast, H., Chilibeck, P. D., Cornish, S. M., Little, J. P., Paus-Jenssen, L. S., Case, A. M. et al. (2009). DXA- 
derived abdominal fat mass, waist circumference, and blood lipids in postmenopausal women.

Obesity.(Silver.Spring), 17, 1635-1640.

Waeber, B., Feihl, F., \& Ruilope, L. (2001). Diabetes and hypertension. Blood Press, 10, 311-321.

Wajchenberg, B. L. (2000). Subcutaneous and visceral adipose tissue: their relation to the metabolic syndrome. Endocr.Rev., 21, 697-738.

Weishaupt, D., Kochli, V. D., \& Marincek, B. (2008). How Does MRI Work? An Introduction to the Physics and Function of Magnetic Resonance Imaging. (2nd ed.) Berlin Heidelberg: Springer-Verlag.

Whelton, S. P., Chin, A., Xin, X., \& He, J. (2002). Effect of aerobic exercise on blood pressure: a meta-analysis of randomized, controlled trials. Ann.Intern.Med., 136, 493503.

World Health Organization (1999). Definition, Diagnosis and Classification of Diabetes Mellitus and its Complications; Part 1: Diagnosis and Classification of Diabetes Mellitus. Geneva, Switzerland: WHO Department of Noncommunicable Disease Surveillance.

Yang, Y. J., Guo, S. J., Ma, J. H., Yuan, L. X., Zhang, J. H., \& Guo, J. (2010). Relationship of five anthropometric indices and blood pressure in an adult Chinese population. Clin.Exp.Hypertens., 32, 504-510.

Zhang, C., Rexrode, K. M., van Dam, R. M., Li, T. Y., \& Hu, F. B. (2008). Abdominal obesity and the risk of allcause, cardiovascular, and cancer mortality: sixteen years of follow-up in US women. Circulation, 117, 1658-1667.

Zhou, Y., Koizumi, N., Kubota, N., Asano, T., Yuhashi, K., Mochizuki, T. et al. (2010). Fast and accurate ultrasonography for visceral fat measurement. Med.Image Comput.Comput.Assist.Interv., 13, 50-58. 